\title{
Membership Categorisation Analysis
}

Robin James Smith

The central concern of 'Membership Categorisation Analysis' (MCA) is the array of categorisation practices observable in naturally-occurring ordinary activities by lay and professional analysts. A central question for MCA is the possibility of social order, handled in and through an attention to the situated, 'always occasioned', accomplishment-in-use of categories, category devices, predicates and collectivities. Whilst it is commonplace to narrowly associate MCA with person descriptions, MCA forms an integral element of a 'live apparatus' (Housley, 2021) in and through which members organise their activities. MCA is thus the study of the organisation of multi-layered, occasioned, categorial-sequential order as the local grounds of 'culture-in-action' (Hester and Eglin, 1997; Housley and Fitzgerald, 2015).

\section{The origins of MCA: Sacks and categorisation practices}

MCA originates in ethnomethodology and Harvey Sacks' original formulations of a Members' categorial 'apparatus' or 'machinery'. Sacks' early analyses considered how relevant categories are 'used' by members to produce and recognise the orderly character of scenes and activities. Categories (of gender, age, 'race' or ethnicity, of political affiliation, religion, profession, occupation, and so on) were, in turn, shown to be used for the organisation of inference and knowledge and, significantly, organised in and through collections and Membership Categorisation Devices (MCDs). That people can and do use categories in specific ways is not a remarkable observation. What distinguishes Sacks' approach, however, is the reorientation to categorisation practices as a topic of inquiry and as a members' rather than analysts' resource. As Sacks (1995[I]: 41-42) remarked:

All the sociology we read is unanalytic, in the sense that they just put some category in. They make sense to us in doing that, but they're doing it simply as another Member ... What they need to do is give us some procedure for choosing that category which is used to present some piece of information. And that brings us back to the question, are there procedures that Members have for selecting categories? One of my aims is to show that there are.

For Sacks, the methodological challenge was not to simply find categories being 'used' but to 'build a model' that provided for that observable categorial order; thus developing a noncognitivist 'primitive science' of categorisation practices, wheresoever they are observed in natural activities. Indeed, Sacks (1995[I]: 115) instructs his students not to 'worry about the brains that these persons couldn't have but which the objects seem to require. Our task is, in 
this sense, to build their brains.' This construction work was no theoretical matter. It was addressed via locating categories as actually organised into devices, collections, and hierarchies in the course of some activity. Sacks thus conceived of culture in a radically alternate manner; as a resource, or 'apparatus for generating recognizable actions' (p. 226). It is this practical character of 'culture' that provides for shared hearings and viewings and thus does not produce 'brains that are roughly alike, but ... alike in fine detail' (p.237). ${ }^{1}$

Across the Lectures, Sacks analyses a range of contexts in which categorisation practices are central: formulating next questions to ask a stranger, ascribing blame and experiencing guilt, 'doing an incongruity', knowing what others are 'thinking', floating problematic identities in conversation, telling a story about an incident at a department store, or reporting a crash on the highway as 'local news'. The key analysis for the building of the 'apparatus', however, was of two sentences of story told by a child to a researcher: "The baby cried. The mommy picked it up."

In a 'self-reflexive' (Hester and Francis, 2003) analysis of the two sentences, Sacks (1972: 216-218) provides several observations: that 'mommy' is heard as the mother of the baby; that this is not a 'ranker sort of subjectivism' but all 'natives' can hear it this way; the two sentences contain two occurrences, with the second following the first; the second occurrence is heard as happening because of the first; and that the sentences fulfil criteria of being a recognisably 'possible description' without further information, insight, or analysis required. Throughout the discussion, and elsewhere, Sacks emphasises how such 'naïve readings' are only the beginnings of (and might be the only beginning for) an analysis that will 'reproduce that activity' (Sacks, 1995[I]: 471).

A central component of that apparatus is that categories can be, and are, routinely organised in and through MCDs: "a collection of categories plus rules of application” (Sacks, 1972: 219). 'Baby' and 'Mommy' are hearable as 'going together' in that they can be heard as 'belonging' to the 'family device'. This collection can then be 'applied' in satisfying the "economy rule" (that a single category from any device can be heard to make adequate reference to a person)

\footnotetext{
${ }^{1}$ There is more to say about Sacks' treatment of 'brains' than there is room, here. Suffice to say, he is not referring to cognitive, 'inner', processes that might be shaped or influenced by culture, some how. Rather he is referring to a shared set of resources and practices; the apparatus. An indicative case is his intriguing discussion of schizophrenics, whom he says "xx". Thus their 'brains' turn out to be just the same as everyone else's.
} 
and "consistency rule" (if a member of a given 'population' is categorised within a particular device, then the other members of that population can be categorised within the same collection). The consistency rule can resolve ambiguity, for instance, in providing for the hearing of 'baby' as a category of the 'family' device rather than only the 'stage of life' device, due to the presence of the second category from that collection ('Mommy'). This operates via a corollary called the 'hearer's maxim'; namely, 'If two or more categories are used to categorise two or more members of some population and those categories can be heard as categories from the same collection then: hear them that way' (Sacks, 1995[I]: 247).

Sacks suggested the actions of the two characters can be heard as 'category-bound activities': 'many activities are taken by Members to be done by some or several particular categories of Members where the categories are categories from membership categorisation devices' (Sacks, 1995[I]: 248-249). This aspect of the relating of observed activities to membership categories is accomplished via the "viewer's maxim"; namely, "If a member sees a category-bound activity being done, then, if one sees it being done by a member of a category to which the activity is bound then see it that way" (Sacks, 1995[I]: 259). The progressivity across the sentences is accomplished in viewers seeing that when 'babies cry' a possible next action is that the mother will 'pick it up'. This is the second viewer's maxim; that if one action can be seen as following another, and the actions can be seen as done by Members that some norm provides for as 'proper' for them to do, then see the Members and the actions that way (Sacks, 1972: 225). The two categories (mother/baby) are also available as what Sacks called a 'standardised relational pair' (SRP: including doctor/patient, teacher/student, husband/wife, and so on). More specifically, Sacks observed that mother/child forms a "collection R" SRP that indicates rights and obligations to ask for and provide help. As Jayyusi (1984) elaborates, there is a moral dimension to category work; i.e. that the mommy should comfort the crying baby, and not doing so may be an accountable matter.

The 'fine and powerful' character of this apparatus can be demonstrated through manipulations of the sentences. If the categories are removed from the story, then the relevant categories can be inferred through the description of actions or activities. In this way, the viewer's maxims provide for a great economy in the telling of a story; for example, "I saw someone getting arrested in town yesterday". The report is routinely recognisable as a 'story-able' event for which the categories "police" and "perpetrator" are relevant for the reported activities to which they are bound, in this instance. 
Such examples taken out of an actual context should, however, be treated as primarily pedagogic. 'Self-reflexive' readings can become overly stipulative and introduce some of the concerns raised by Schegloff (1995[I]) regarding analytic promiscuity. Such concerns have, however, regularly being refuted in work that demonstrates members' flexible orientations to categories and 'bound' activities in such a way that renders categorisation practices resistant to systemisation (see Fitzgerald, 2012). The central methodological point, for now, is that categories, categorisation devices, and associated practices are routinely discoverable-in-use in the range of human activities accomplishing the production/recognition of social knowledge and practical order. It is the recognition of the always-occasioned-character of Members' category work that has driven the development of MCA 'after Sacks'.

\section{MCA: the 'radically local' orientation to categorisation practices}

The term 'MCA' was coined by Peter Eglin and Stephen Hester (1992) as an alternate formulation of Sacks' original MCD analysis. The term indicated a re-oriented and renewed ethnomethodological attention paid to the intelligibility of category devices as a dynamic, reflexive, and occasioned accomplishment. In other words, whilst categories can be organised into some collection, that collection will also be intelligible through the categories that it collects (Francis and Hester, 2017). MCA thus covers the array of Members' categorisation practices, and starts and ends with analyses that are, in the first instance Members' analyses of their situation (Eglin and Hester, 1999), in whatever form they are observable, in any given context, which, of course, includes the doing of professional sociology (see, for example Housley and Smith, 2015).

MCA develops as part of a critical response to elements of Sacks' original analyses and advances key studies of categorisation practices following Sacks' premature death (e.g. Watson, 1978; Drew, 1978; McHoul and Watson, 1984). The direction of travel was toward studies of the actual occasions of the accomplishment of categorial order (including, prominently, non-person categorisations and collections). ${ }^{2}$ MCA also represents a critical engagement with unintended consequences of Sacks' treatment of categories in passages where he makes seemingly decontextualized analytic distinctions and stipulations regarding MCDs

\footnotetext{
${ }^{2}$ Although see Francis and Hester's (2017) compelling argument for the continued pedagogic value of 'selfreflexive' analyses.
} 
(e.g., Sacks (1995[I]: 238). Readings of these passages, and 'applications' of MCA, can lead to the sense that those categories and their devices are 'culturally organised', somewhat static and even nomothetic - in a similar manner to social anthropological conceptions - with the analytic consequences being the treatment of categories and devices as stable 'structures' to be 'found' by the analyst in the materials, and the mistaken notion that that might count as a finding.

The central issue for MCA - and, indeed, in Sacks' own analyses of the occasioned character of category work (e.g. the discussion of 'character appears on cue' [1995[I]: 182-7]) - is that such a rigid formulation loses the ethnomethodological notion that members are not straightforwardly 'selecting' categories which then have 'meaning' attached to them 'in context' (Watson, 2015). Rather, local category work displays and constitutes context, and the meaning of a given category, and its organisation into some relevant device, accomplished in and as the ongoing flow of a specific activity. MCA thus addresses the conjoined methodological troubles of de-contextualisation and culturalism, not through restrictive methodological prescription but through a flexible, radically local orientation to 'culture-inaction' (Hester and Eglin, 1997).

For MCA studies, the categorial 'machinery' briefly outlined above is (re-)conceptualised as 'improvisational cultural practices' (Francis and Hester, 2017: 57), rather than something rigid or tool-like that members carry with them and 'apply' or 'adapt' to whatever setting they find themselves in. Categories, their relationship to collections, and, indeed, the 'rules' of application are not necessarily 'invented' on the spot but, equally, should be treated as produced and recognised for 'another first time'. As Hester and Eglin (1997: 20) put it:

Members [do not] use culture to do things... culture is constituted in, and only exists in, action. For membership categorisation analysis, this means that the orderliness of cultural resources ... is constituted in their use rather than preexisting as a machinery for whatever uses members might want to put them to.

In this vein, recent MCA studies have explicated the multi-layered contexture of categorisation practices and their co-constitutive relation to sequential order for the contours of social interaction (Housley and Fitzgerald, 2002; 2015) across a diverse range of contexts including educational settings (Hester and Francis (eds), 2000), family meal times (Butler and Fitzgerald, 
2010), complaint calls (Stokoe, 2009), and disputes (Reynolds and Fitzgerald, 2015; Smith, 2017), in sporting settings (Evans and Fitzgerald, 2017), and in using new communication technology (Licoppe, forthcoming). Key analytic developments include a sustained attention to 'omni-relevant devices', as well as Members' treatments of the commonsense knowledge social structure and morality in relation to gender and violence (Stokoe, 2010), 'race' (Robles, 2015), and age and ageing (Nikander, 2002) inter alia. This recent work is also characterised by an 'inter-disciplinary' dialogue which is, arguably, in keeping with Sacks' own intellectual orientations (Smith et al, 2021). There is no room to describe these current developments in detail, but in the following section I consider an example where a number of these concerns are present for Members-as-analysts in the viewing of an online video.

\section{MCA-in-action: the baby came in, the mommy/nanny picked it up?}

The following example is from a video of a televised interview between a studio host and an expert on Korean affairs - interrupted by the interviewee's children entering the room. The video was subsequently posted on YouTube and went 'viral'. The clip begins someway into the interview with Professor Robert Kelly (RK) answering questions relating to a recent scandal and its impact on South Korea's policy toward North Korea (his area of expertise). The interruption begins when a child opens a door and 'dances' into the room. The host $(\mathrm{H})$ and RK attempt to continue the interview, with RK putting his arm across the child, moving them to the side. Presently, a second younger child wheels themselves into the room in a 'stroller', followed by a woman who rushes in, grabs the children and hurries them out before reaching back in and closing the door. The whole episode lasts around 43 seconds.
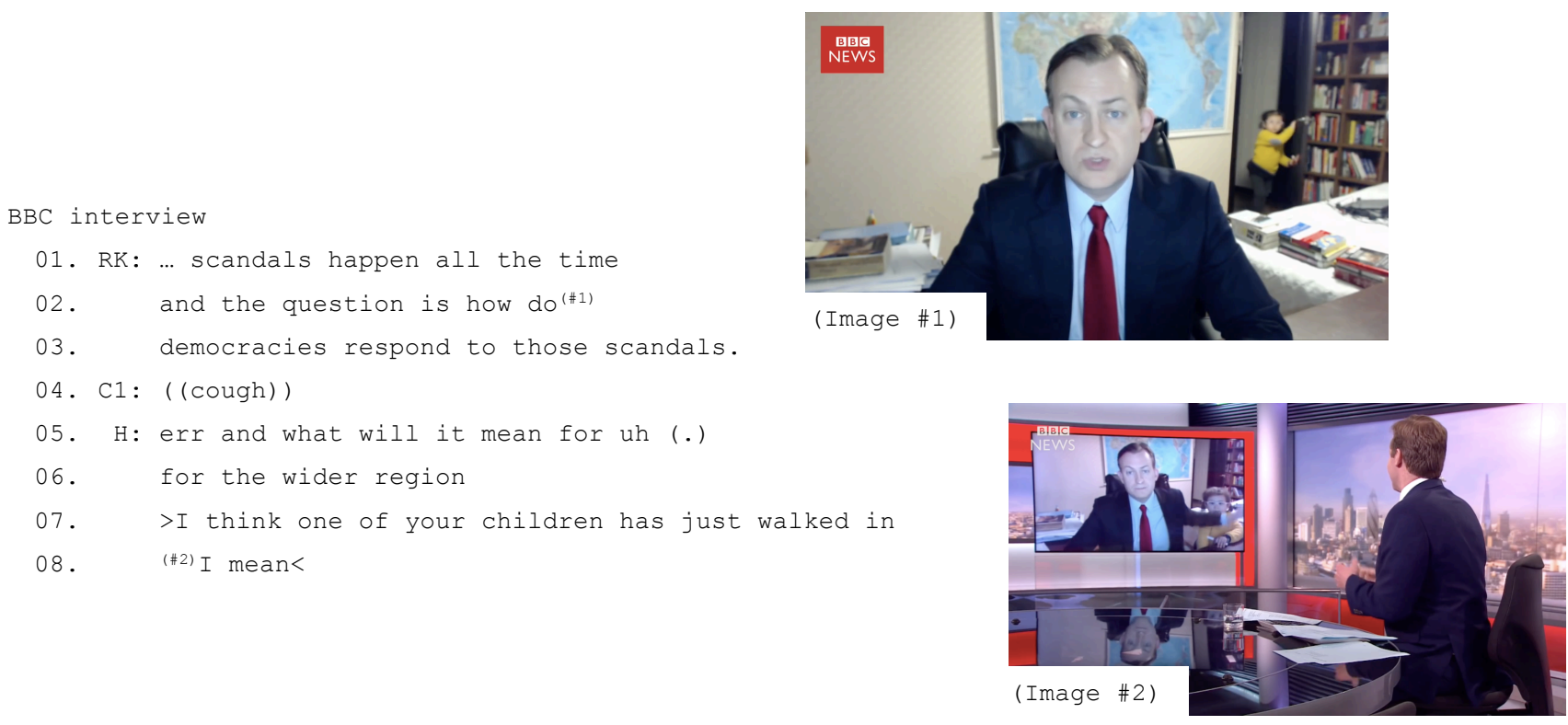

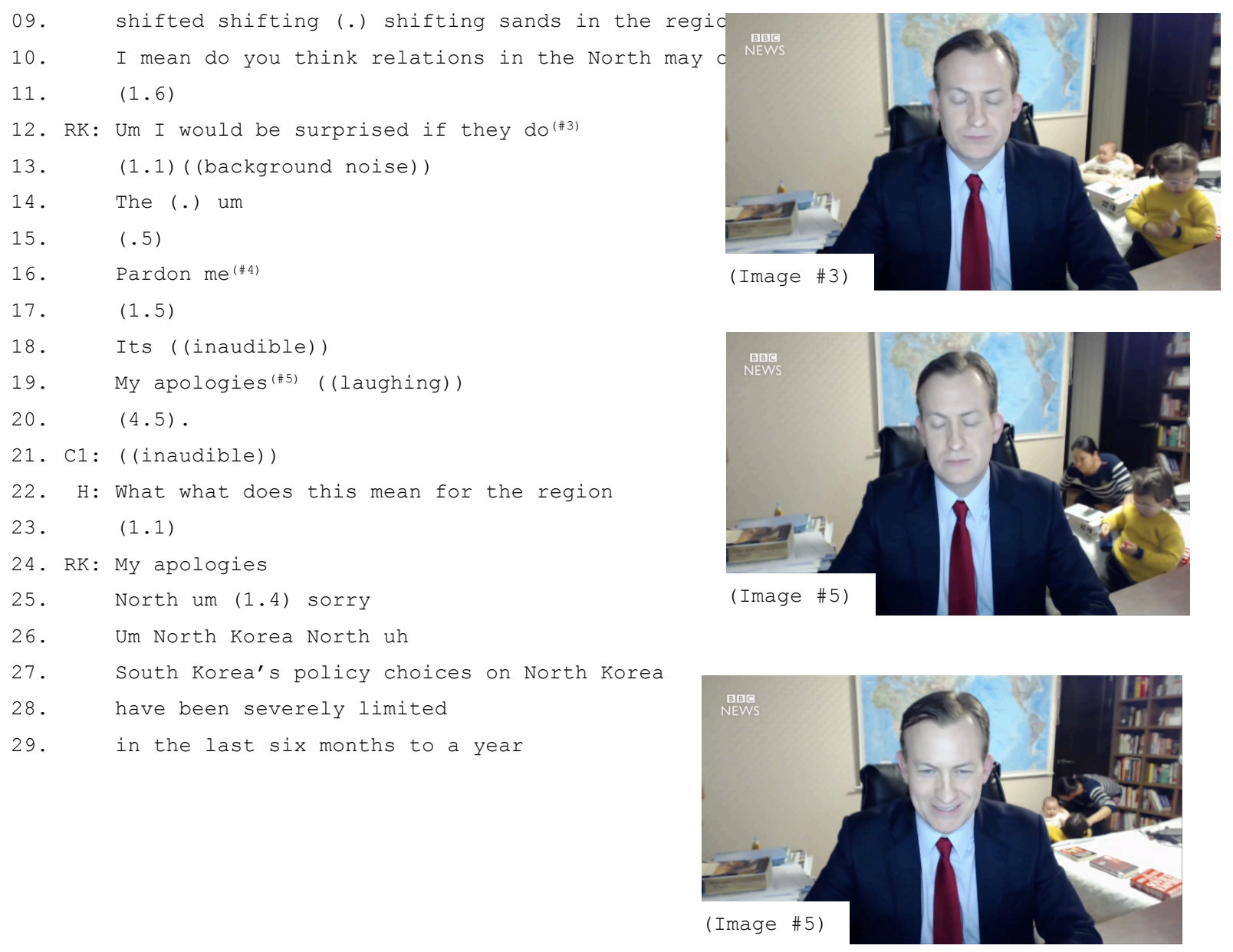

The entrance of the first child (C1) occasions the interruption of the 'flow' of the interview, and a questioning turn (line 7-8, image 2). In describing the child as the child of RK, H makes available the category 'father' and accomplishes-in-use the 'family' device as relevant for this scene. In this way, RK is now categorizable both as 'father' and 'interviewee' in a multi-layered sense (Housley and Fitzgerald, 2015), which produces some problems for the actions that follow. Despite the disruption, however, the turns between RK and $\mathrm{H}$ display a continued orientation to the 'context' of the interview and 'turn-generated categories' (Watson, 1992), 'interviewer' and 'interviewee'. Significantly, the production/recognition of such categories draws attention to how Members' do not 'act out' pre-defined 'roles' in interaction, but, rather, how the categories of 'interviewer' and 'interviewee' are observable in how the sequential slots of the emergent interaction are occupied. Participants display an orientation both to the sequential order of the interview, and the presence of an SRP (that is the obligation of 'interviewer' to ask and 'interviewee' to answer questions as part of a televised interview), as a resource for keeping the interaction 'on track' (with difficulty in doing so marked by repetition and significant pauses). 
This example also displays an "omni-relevant device" (Sacks, 1995[I]: 312 - 319), a term referring to how certain category pairs (in this instance 'interviewee/interviewer') and their devices ('the interview') can be treated of as a 'controlling device' in that there is "no way of excluding its operation when it is relevant". Whilst other devices may be present (in this case 'family'), omni-relevant devices remain relevant throughout the interaction, both at the 'institutional level' - i.e. a 'televised interview' - and at the turn-by-turn level in the observable turn-generated categories.

We might also consider how the categorisability of the setting, and the co-consitutive character of that categorisation for categorising its Members, is itself occasioned in and through the disruption. When the first child is pushed back by RK to the edge of the bed, they sit down dislodging some books that had been placed there. This was topicalised by viewers commenting on the video as 'revealing' that the interview was taking place in a bedroom 'disguised' as an office. Whilst adding to the comedic value of the video, the revealing of the setting as 'domestic' demonstrates how categories, devices, and categorisation practices are themselves part of an emergent 'Gestalt contexture': the setting yields categories and their relevancies (Garfinkel, 2002; Watson, 2005). Categories and devices are not and cannot be 'decided' by individual viewers externally to what might be thought of as the 'scene'.

Whilst the categorisation of the infants as RK's children and not just any children was interestingly unproblematic, categorial trouble emerged in relation to the 'identity' of the woman who removed the children from the room. In contrast to my intentionally neutral description of the event above, in the context of this emergently 'domestic' setting other candidate categorisations are available. Rather than leaving this decision to the analyst (after all, $\mathrm{H}$ does not comment on the woman's appearance), one of the affordances of analysing social media videos is the opportunity to access a distributed public's categorial reasoning and accounting work in relation to a given phenomenon.

The following are excerpts from the comments thread built following user 'A' posting: " $\mathrm{I}$ think the Mom is the true star".

\footnotetext{
${ }^{3}$ It is not easy to replicate the sequentiality of comment threads. Their asynchronous character means it is sometimes difficult to determine which 'turn' a 'speaker' is responding to. I have not included usernames here, but have simply labelled them alphabetically, indicating to whom a comment is directed.
} 
Comment thread example 1:

1. B: they all are - but the two kids are awesome

2. C: A- me too

3. D: A- mom? Or Nanny?

4. E: B- She's the mother

The initial categorisation of the woman as 'Mom' is treated unproblematically by the first two responding comments, but directly questioned in the third where D proposes an alternate categorisation of 'Nanny'. Whether or not 'Nanny' 'belongs' in the 'family device' with 'Mom' is less important than the observation that both categories are occasioned by the observable actions of the woman in relation to the children: 'dealing with children' is a 'category-bound predicate' of both categories. ${ }^{4}$ Despite satisfying the 'relevance rule' (Sacks, 1972) the procedural consequentiality of candidate categories in terms of the viewing and assessment of the event, remains a 'live' issue for members.

Comment thread example 2:

1. F: I thought she was his maid

2. G: This is open stereotyping - as long as she is Asian, she must be the maid.

3. This is racism and your are a racist

4. F: boo hoo

5. G: Boo hoo to yourself! Hit your true thoughts? And that's why you had to repeat the

6. Same words twice?

7. F: lol, faggot.

8. G: Loser!

In Example 2 the introduction of a further category 'Maid' (also related to the 'domestic' device) is challenged through the invocation of the racial category 'Asian' and, thus, the 'race' device. In this sense, the category 'Asian' is not only heard as a racial category, providing for the accusation of stereotyping and racism, but also demonstrates a Members' orientation to the reflexivity between category and predicate - that is, $\mathrm{G}$ can claim that $\mathrm{F}$ is seeing the woman as a Maid not only because of the observable activity, but because, in his viewing at least, she is also 'perceptually assignable' to the category Asian (which has occasioned the category 'Maid').

\footnotetext{
${ }^{4}$ Reynolds and Fitzgerald (2015) have highlighted distinctions in how Members relate categories to category features, between 'category tied' (a link between category and category feature not taken-for-granted and needs to be made explicit), 'bound' (a taken for granted link, which is still made explicit), and 'category predicate' (a category feature is implied through a category or device).
} 
In these and similar short lived, distal disputes, we see something of what Sacks (1995) identified in the practice of 'categorising the categoriser'. Although Sacks only discusses relative or hierarchical categories (such as the age of a speaker in relation to the category 'old'), Whitehead (2009: 328) demonstrates how the use of racial categories by a non-incumbent 'can result in what the speaker is saying being discounted as "biased" or "racially motivated" on the basis of the speaker's own racial identity'. In this example, the commenter's race is not necessarily available to co-viewers, but the account in example 2 is designed in such a way that it assumes that the categoriser of the woman as a 'Maid' is 'not-Asian' and likely 'white' (an observation possibly supported by them not claiming co-incumbency in the "Asian" category when accused of being racist in response). Similarly, in a final example, the use of the category 'Nanny' occasions a consequent categorisation of the categoriser as 'another racist'. In this case, the 'bounded-ness' of the category 'racist' to the action of 'seeing' the woman as a nanny is refuted by a third-party ' $\mathrm{J}$ ' constructs a counter 'version of the world' (no less), via recourse to invoking 'commonsense knowledge' relating to the likelihood of an Asian woman being a Nanny for a white man in a more general sense.

Comment thread example 3:

1. H: mum ? you mean nanny

2. I: H- : here comes another racist

3. J: How can thinking she is a nanny instead of the mother be racist? Hate to disappoint your version of the world but many Asians are employed as nannies by whites. This may not be the case but it certainly was my 1st thought too ...

4. K: J - if she was Caucasian, would you think she was a nanny?

This case demonstrates Members' orientations to categorial 'promiscuity' in categorising others and their actions, as well as how Members' topicalise the consequentiality of that categorisation work through the introduction of further devices. Matters of categorial 'promiscuity', devices as 'wild phenomena', and the assembly and 'testing' of associated rules of application are relevant concerns only in-so-far-as they are concerns for Members in and for a given activity.

\section{MCA and its futures}

Across this chapter MCA has been introduced not as a systemised process of analysis to be 'applied' by sociologists but as a rigorous, flexible, and generative set of practical methods, accomplished-in-use by Members in the lay and professional observation and description of social life. Mindful of Watson's (2015) well-placed concerns with the potential reification of 
categories under the rubric of MCA, it is essential that studies of categorisation practices retain their primarily ethnomethodological and sociological character (see also MacBeth, this collection). In taking MCA forward, it is necessary to incorporate a further range of materials and settings into the corpus of studies in such a way that keeps apace with Members' own innovations and inquiries. Indeed, part of the reading and critique of Sacks' work as 'static' emerges from the focus on transcripts of disembodied Members' talk, either on the telephone or in relatively stable and fixed contexts. Yet, categorisation practices remain central to a whole host of organisational matters in mobile contexts, for example, in which categorial practices and relevancies can be observed in operation without talk; the queue, of course, being a key perspicuous setting in which turn-generated categories, and category-generated turns can be observation in action.

There are very few 'MCA-oriented ethnographic studies' yet, as clearly outlined by Sacks, the practice of observation itself is accomplished through categorisational practices (Smith, 2021). Categories permit you to see (Sacks, 1995[I]: 42), and so the further analysis of embodied categorial practices in producing/recognising social action, seems one avenue of future contribution for MCA oriented work. There remains a good deal of work to be done in terms of the categorial organisation of space and mobility (although there has been much promising work in this area too), and the relationship between categorisation practices and various modes of perception including, but not limited to, the visual. The digital era brings with it new interactional contexts and new materials for existing methods (Housley, 2021), highlighted, in part, by the affordances of social media for accessing distributed category work in relation to mundane 'viral' videos.

There are, of course, continued debates relating to the status of MCA as an analytic enterprise in relation to EM and CA, and to the trajectory of Sacks' own work. These turn on issues relating to whether it is necessary or indeed desirable to work with collections rather than single cases, and, notably, the requirement, or not, to systematise MCA (see Stokoe, 2012). What is certain is that an attention to membership categorisation practices has found a home within the study of naturally occurring interaction and social organisation. What was once treated as a niche concern has been adopted, incorporated, and developed across a number of fields. The key point, however, is that as studies of MCA develop, the 'tools' such as those outlined in this chapter are not to be stipulated by methodological statements or prescriptions but, rather, 'the 
relevant analytic tools are assembled by the analyst in relation to the particular data being examined, as occasioned by the data' (Housley and Fitzgerald, 2015: 15).

\section{References:}

Butler, C. W., \& Fitzgerald, R. (2010). Membership-in-action: Operative identities in a family meal. Journal of Pragmatics, 42(9), 2462-2474.

Drew, P. (1978). Accusations: The occasioned use of members' knowledge of religious geography in describing events. Sociology. 12(1), 1-22.

Eglin, P., \& Hester, S. (1992) Category, predicate and task: The pragmatics of practical action. Semiotica 88(3/4), 243-268

Evans, B., \& Fitzgerald, R. (2017). The categorial and sequential work of 'embodied mapping' in basketball coaching. Journal of Pragmatics. 118, 81-98.

Fitzgerald, R. (2012). Membership categorization analysis: Wild and promiscuous or simply the joy of Sacks? Discourse Studies, 14(3), 305-311

Francis, D., \& Hester, S. (2017). Stephen Hester on the problem of culturalism. Journal of Pragmatics, 118, 56-63.

Garfinkel, H. (2002) Ethnomethodology's program: Working out Durkheim's aphorism. Lanham, Maryland: Rowman \& Littlefield Publishers

Hester, S. \& Elgin, P. (1997). Membership Categorisation Analysis: An Introduction. In S. Hester \& P. Eglin. (Eds.) Culture in action: Studies in membership categorization analysis. pp. 1-23. Washington, DC: University Press of America.

Hester, S. K., \& Francis, D. (Eds.). (2000). Local educational order: Ethnomethodological studies of knowledge in action (Vol. 73). Amsterdam: John Benjamins Publishing.

Hester, S., \& Francis, D. (2003). Analysing visually available mundane order: A walk to the supermarket. Visual studies, 18(1), 36-46.

Housley, W. (forthcoming). Harvey Sacks, membership categorisation, and social media. In in R. J. Smith, R. Fitzgerald, W. Housley (eds.) On Sacks: Methodology, materials, and inspirations. London: Routledge

Housley, W., \& Fitzgerald, R. (2015). Introduction to membership categorisation analysis. In R. Fitzgerald \& W. Housley (Eds) Advances in membership categorisation analysis. pp. 1-22. London: SAGE

Housley, W., \& Fitzgerald, R. (2002). The reconsidered model of membership categorization analysis. Qualitative Research, 2(1), 59-83. 
Housley, W., \& Smith, R. J. (2015) Membership categorisation and methodological reasoning in research team interaction. In R. Fitzgerald and W. Housley (eds.) Advances in membership categorisation analysis (pp. 151-174). London: SAGE Jayyusi, L. (1984). Categorization and the moral order. London: Routledge \& Kegan Paul. McHoul, A. \& Watson, D. R. (1984). Two axes for the analysis of 'commonsense' and 'formal' geographical knowledge in classroom talk. British Journal of Sociology of Education. 5(3): 281-302.

Nikander, P. (2002). Age in action: Membership work and stage of life categories in talk. Helsinki: Suomalaisen tiedeakatemi

Reynolds, E., \& Fitzgerald, R. Challenging normativity: Re-appraising category, bound, tied and predicated features. In R. Fitzgerald and W. Housley (eds.) Advances in membership categorisation analysis (pp. 99-122). London: SAGE

Robles, J. S. (2015). Extreme case (re) formulation as a practice for making hearably racist talk repairable. Journal of Language and Social Psychology. 34(4), 390-409.

Sacks, H. (1995) Lectures on Conversation (Volumes I and II). Edited by G. Jefferson with introduction by E. A. Schegloff. Oxford: Blackwell.

Sacks, H. (1972) On the analyzability of stories by children. In J. J. Gumperz \& D. Hymes (Eds.) Directions in Sociolinguistics (pp. 325-345). New York: Holt Rinehart and Winston.

Schegloff, E.A. (1995). 'Introduction' in Sacks, H. (1995[I]) Lectures on Conversation. pp. ix1xii. Oxford: Blackwell

Stokoe, E. (2012). Moving forward with membership categorization analysis: Methods for systematic analysis. Discourse studies, 14(3), 277-303.

Stokoe, E. (2010). 'I'm not gonna hit a lady': Conversation analysis, membership categorization and men's denials of violence towards women. Discourse \& Society. 21(1), 59-82.

Stokoe, E. (2009). Doing actions with identity categories: Complaints and denials in neighbor disputes. Text \& Talk. 29(1), 75-97.

Smith, R. J. (2017). Membership categorisation, category-relevant spaces, and perception-inaction: The case of disputes between cyclists and drivers. Journal of Pragmatics. 118: 120-133.

Smith, R. J., Fitzgerald, R., Housley, W. (2021). On Sacks: Methodology, Materials, and Inspirations. In R. J. Smith, R. Fitzgerald \& W. Housley (eds.) On Sacks: methodology, materials, and inspirations. London: Routledge 
Watson, R. (2015). De-reifying categories. In R. Fitzgerald \& W. Housley (eds.) Advances in membership categorisation analysis (pp. 23-50). London: SAGE

Watson, R. (2005). The visibility arrangements of public space: Conceptual resources and methodological issues in analysing pedestrian movements. Communication and Cognition. 38(3-4): 201-229

Watson, R. (1978). Categorization, authorization and blame-negotiation in conversation. Sociology 12(1): 105-113

Whitehead, K. A. (2009). "Categorizing the categorizer": The management of racial common sense in interaction. Social Psychology Quarterly. 72(4): 325-342. 